\section{OPTIMAL UTILIZATION OF TIMBER POLES AS STRUCTURAL MEMBERS OF FORMWORK}

\author{
Ladislaus Lwambuka \\ Email:1lwambuka@yahoo.de
}

poles used for the construction of floor slabs. That notwithstanding, the timber used as formwork is usually disposed as a waste upon accomplishment of the curing process. This un-economical practice calls for a need to establish on how timber utilization as structural members of formwork can be optimized.

\section{OBJECTIVE OF THE STUDY}

The objective for which this study has been carried out is twofold; firstly to investigate the extent to which timber poles are being utilized as structural members of formwork, and secondly to investigate the suitability of "Mirunda" poles on basis of the load bearing capacity and availability in terms of material sources and supply. The findings of the study generate valuable recommendations on the rational utilization of timbers poles as structural members of formwork.

\section{METHODOLOGY}

The study has involved a survey of the existing "Mirunda" poles on the market at street side vendors on various locations in Dar es Salaam. Samples of the materials have been collected for testing at the Structural Engineering Materials Laboratory, University of Dar es Salaam. The lab tests were aimed to investigate the following:

i. Quality features of the timber poles used.

ii. Mode of structural failure when subjected to axial loading.

On the other hand surveys were conducted at randomly selected construction sites where timber formworks are being applied to support the casting of reinforced concrete floor slabs. The aim of the survey was to establish the existing common features of timber poles as structural formwork supporting floor slab casting with reinforced concrete. Fig. 1 is one of the typical formworks of "Mirunda" poles supporting a freshly cased reinforced concrete floor slab.

\footnotetext{
${ }^{1}$ Dr.-Ing., Senior Lecturer, Department of Structural

Engineering, University of Dar es Salaam
} 


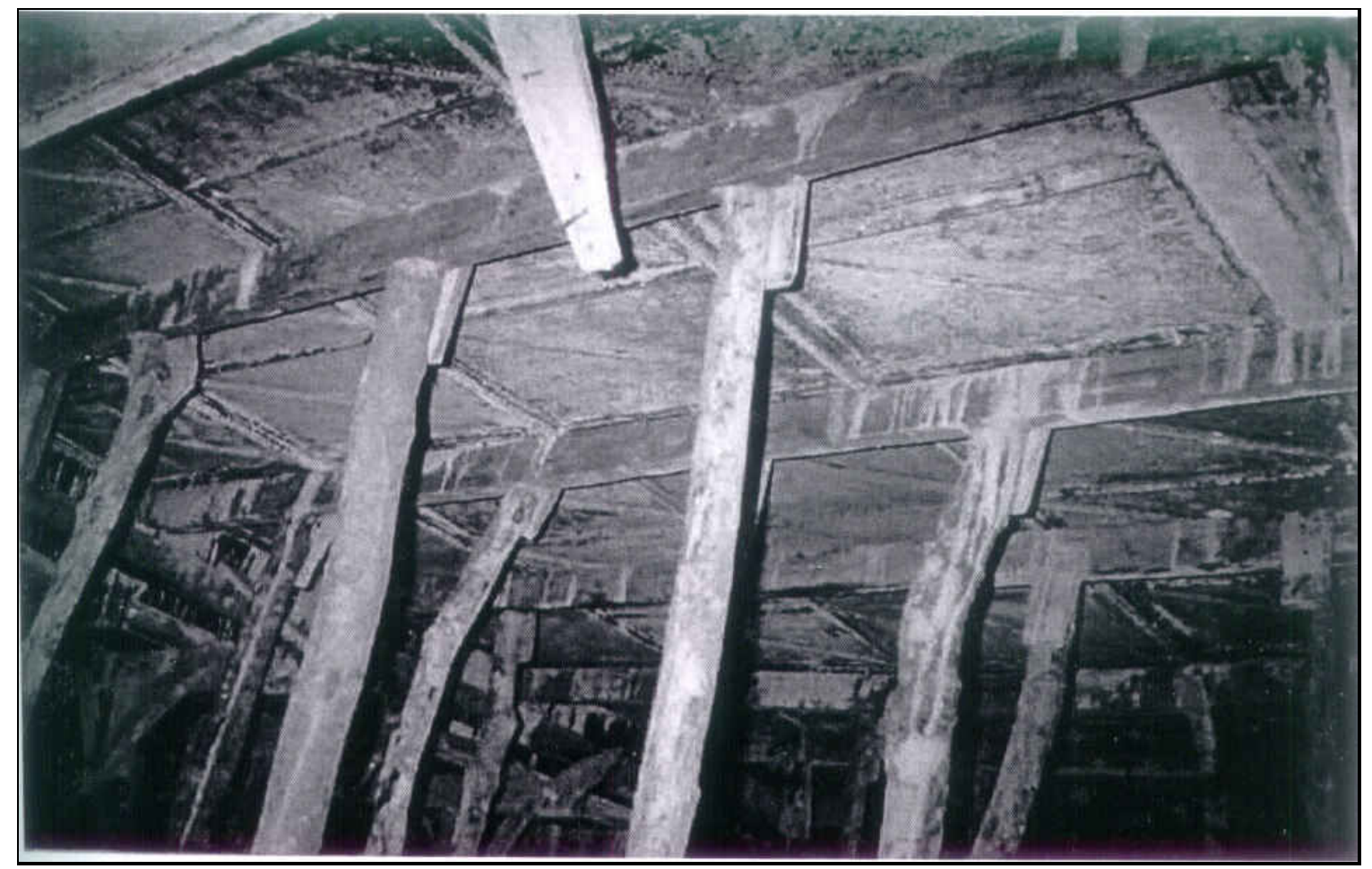

Fig. 1: One of the typical construction sites with "Mirunda" formwork supporting a reinforced concrete slab.

Specifically the survey involved the following observations:

i. Timber pole installations and support conditions at both ends of the column, poles in conformity with the guidelines by Desch (1981) on "Timber Utilization"

ii. The quantity of timber poles used to support the casting of floor slabs and beams,

iii. The quality of timber poles used for the construction of structural formwork, the properties of which are specified by Findlay (1974),

iv. The dead and imposed loads as prescribed in BS 6399: Part1 (1984).

The site survey and laboratory investigations provided basis for assessing not only the suitability of timber poles as structural members of formworks but also developing indicatively the optimum requirement of timber poles in support of reinforced concrete casting.

\section{ANALYTICAL CONSIDERATION}

\subsection{Instability of Compression Members}

A statically stable member subject to compression may become elastically unstable when the compression load becomes high enough. Even an entire rigid formwork may become elastically unstable if compression forces get high enough in some or all of the members.
The case at hand refers to this type of instability It is further known that the problem of instability becomes more critical when the compressed structural members are geometrically slender; and in this case the structural member, which is stressed initially in uniform compression, must remain perfectly straight if it is to be in equilibrium without internal moment. Any tendency of the shape to depart from the action line of the compression forces induces bending in the structural element and the bending moment has an increasing effect to the deflection. If the bending stiffness of the slender member is not sufficient, then the member undergoes sudden large lateral displacement at a certain stress level. This behaviour of structural instability is called elastic buckling if the critical stress is below the stress-strain-curve and in-elastic buckling if the critical stress is between the proportional limit and the yield limit.

\section{The Critical Loading}

When the bar is subjected to a compressive axial force $F$, it should stay straight as long as $F$ is below the critical buckling load $F_{c r}$.

From the relationship between the critical buckling force and deflected shape

$$
y_{(x)}^{\prime \prime}+\frac{F_{c r}}{E I} y_{(x)}=0
$$

We attain the Euler solution for the critical buckling force of a simply supported column. 


$$
\begin{aligned}
F_{c r}=\frac{\pi^{2} E I}{l^{2}} \quad \text { (2.2) } & \text { with } \quad l=\text { span length } \\
& E=\text { Modulus of elasticity } \\
& I=\text { Moment of inertia }
\end{aligned}
$$

In the event the axial compressive force in any one pole is larger than $F_{c r}$, the whole set of results would have no physical meaning because this particular pole would have buckled and ended its load carrying participation.

In this study we are going to establish when the timber formwork becomes incapacitated due to buckling.

\subsection{The Critical Buckling Stress}

The corresponding buckling stress can be derived from the buckling load as

$$
\sigma_{c r}=\frac{F_{c r}}{A}=\frac{\pi^{2} E I}{A l^{2}}
$$

with $A=$ Cross sectional area

By introducing a new section property, the so called radius of gyration

$$
r=\sqrt{\frac{I}{A}}
$$

we get the slenderness ratio

$$
\lambda=\frac{l}{r}
$$

so that the relationship between the critical stress and slenderness ratio is given by the Euler's hyperbola as

$\sigma_{c r}=\frac{\pi E}{\lambda^{2}}$

It is worth noting that under real situations there is no uniformity of section properties along the longitudinal axis of a "Mirunda" pole. However for the purpose of this investigation, a careful selection of the poles with minimum variation of section diameters has been undertaken.

\section{LABORATORY TESTING}

The load bearing capacity of timber poles were established through laboratory testing at the Structural Engineering Materials Laboratory, University of Dar es Salaam, the set-up of which is indicated in Fig.2. The results obtained were the average critical load $F_{c r}$ at buckling from a series of timber poles lengths.

The average critical compressive stress $\sigma_{c r}$ corresponding to the timber pole lengths were then obtained from (2.3). The slenderness ratio was computed therefrom as per (2.5).

The results obtained are presented in Table 1:

Table 1: The slenderness ratio for selected timber poles

\begin{tabular}{|l|l|l|}
\hline $\begin{array}{l}\text { Length of timber pole } \\
(l)[\mathrm{m}]\end{array}$ & $\begin{array}{l}\text { Critical compressive stress } \\
\left(\sigma_{c r}\right)\left[\mathrm{N} / \mathrm{mm}^{2}\right]\end{array}$ & $\begin{array}{l}\text { Slenderness ratio } \\
(\lambda)[-]\end{array}$ \\
\hline 2.2 & 4.5 & 140 \\
\hline 2.0 & 16.9 & 125 \\
\hline 1.8 & 7.5 & 118 \\
\hline 1.6 & 7.5 & 95.5 \\
\hline 1.4 & 7.8 & 86.2 \\
\hline 1.2 & 10.8 & 72.7 \\
\hline 1.0 & 15.0 & 58.0 \\
\hline
\end{tabular}




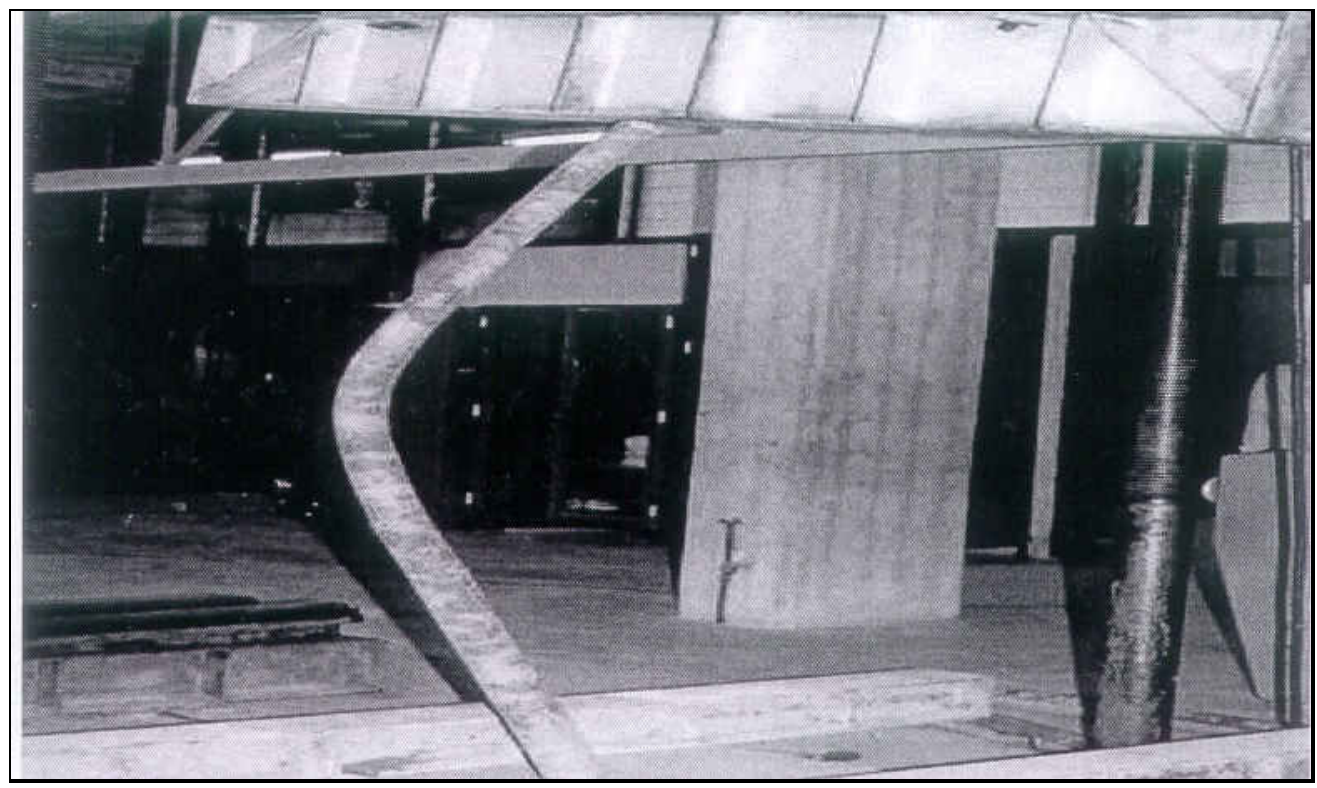

Fig. 2: Laboratory testing to establish the buckling load for "Mirunda" poles.

While the laboratory testing facility was limited at the test element height of $2.2 \mathrm{~m}$ the actual height on site was $2.85 \mathrm{~m}$ for the floor slab and $2.55 \mathrm{~m}$ for the beam. The actual slenderness ratio $\lambda_{\mathrm{s}}$ for the slab poles and $\lambda_{b}$ for the beam poles were therefore obtained graphically from Fig. 3.

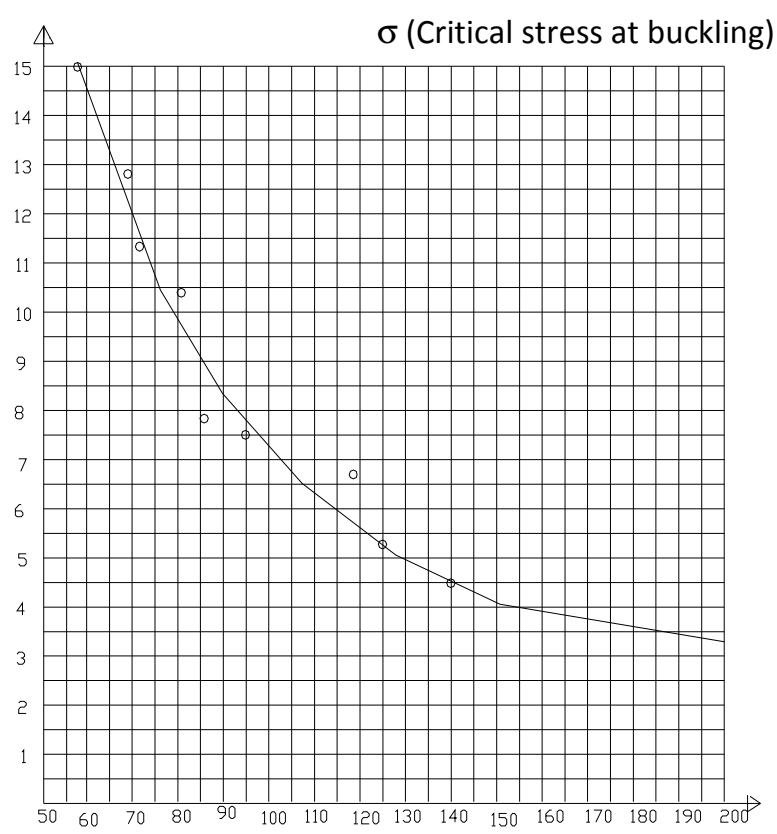

Fig. 3: $\sigma-\lambda$ experimental results curve

The corresponding values for the actual timber poles' sizes on site have been obtained through interpolation of the curve in Fig. 3 as follows:

$$
\begin{array}{ll}
\lambda_{\mathrm{s}}=\frac{l}{r}=\frac{2850}{14.66}=194.4 & \sigma_{\mathrm{cr}}=3.3 \mathrm{~N} / \mathrm{mm}^{2} \\
\lambda_{\mathrm{b}}=\frac{l}{r}=\frac{2550}{14.66}=173.9 & \sigma_{\mathrm{cr}}=3.7 \mathrm{~N} / \mathrm{mm}^{2}
\end{array}
$$

Subsequently the load bearing capacity for the actual timber poles lengths were established as follows, with $A=2922 \mathrm{~mm}^{2}$ as the average cross sectional area for the timber poles.

Floor slab poles: $\left.2922 \mathrm{~mm}^{2}\right)=9.6 \mathrm{kN}$

Floor beam poles: $\quad F_{c r}=\sigma_{\text {cr }} \mathrm{A}=\left(3.7 \mathrm{~N} / \mathrm{mm}^{2} \mathrm{x}\right.$ $\left.2922 \mathrm{~mm}^{2}\right)=10.8 \mathrm{kN}$. 


\section{DETERMINATION OF TIMBER POLE'S REQUIREMENT}

\subsection{Site Survey}

The results of this study are based on the actual typical construction sites visited

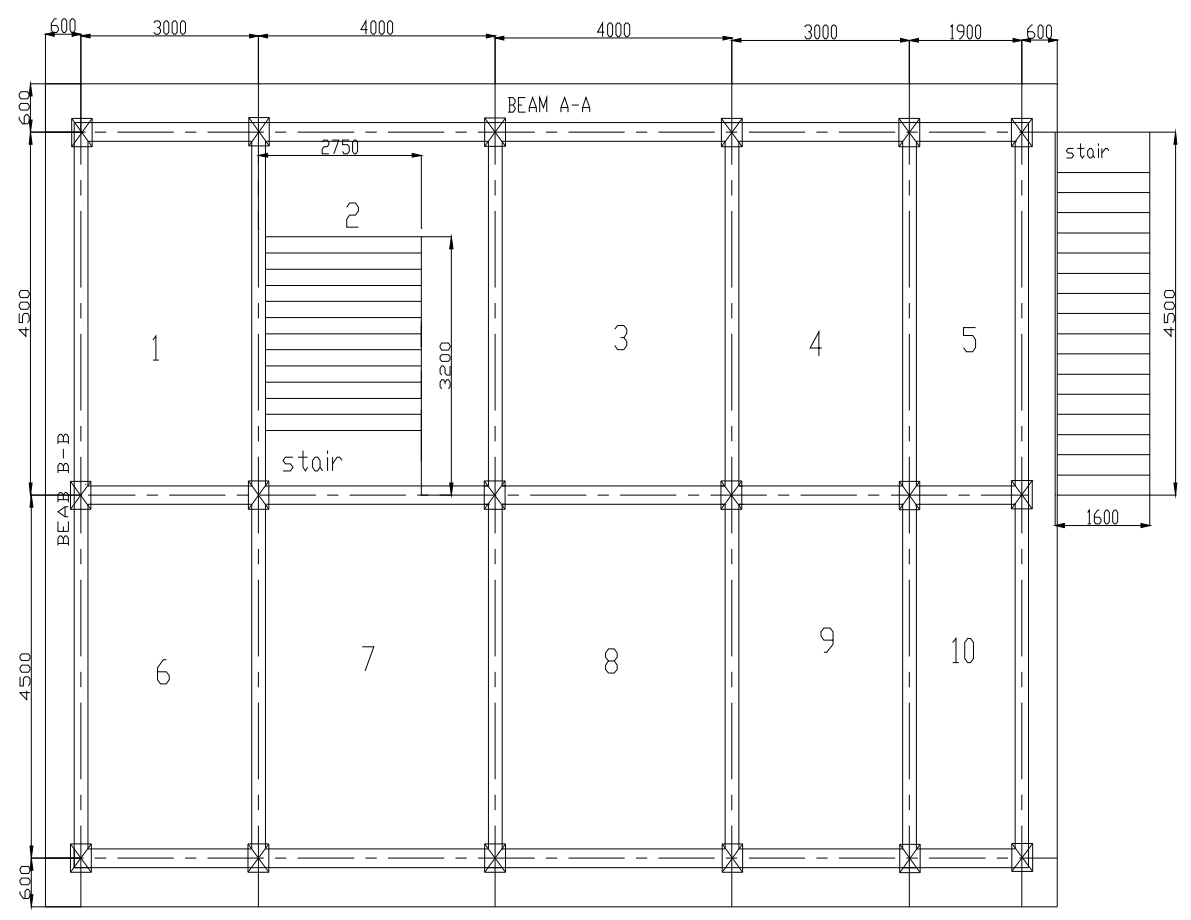

Fig. 4: Floor plan on site

The optimal requirement of timber poles has been obtained using the following approach:

Weight of freshly coasted concrete $\mathrm{W}_{\mathrm{d}}=\varsigma$. A. $\mathrm{d}$ with $\varsigma=$ density of concrete $\left(24 \mathrm{kN} / \mathrm{m}^{3}\right)$

$A=$ area of slab panel / beam

$\mathrm{d}=$ the height of slab / beam

Weight of imposed load $\mathrm{W}_{\mathrm{P}}=\mathrm{P}$. A with $\mathrm{P}=4 \mathrm{kN} / \mathrm{m}^{2}$

The optimal number of timber poles required is given by (2.7) using the ultimate load capacity

$$
n=\frac{1.4 \bullet W_{d}+1.6 \bullet W_{p}}{\sigma_{c r} \bullet A_{m}}
$$

with $\sigma_{\mathrm{cr}}=$ critical timber pole stress at buckling $\mathrm{A}_{\mathrm{m}}=$ average cross sectional area of timber poles

\subsection{Investigation Results}

Results obtained from the laboratory tests indicate the amount of timber poles required to support the freshly casted reinforced concrete. Table 2 below provides a comparison of the actual timber poles used on site and the amount required as per load bearing compressive capacity. 
Table 2: The optimal requirement of "Mirunda" poles as percentage of the actual observation on site

\begin{tabular}{|l|l|l|l|l|}
\hline \multirow{4}{*}{$\begin{array}{l}\text { Site } \\
\text { no. }\end{array}$} & \multirow{2}{*}{$\begin{array}{l}\text { Structural } \\
\text { element }\end{array}$} & $\begin{array}{l}\text { No. of "Mirunda" } \\
\text { poles counted on site }\end{array}$ & $\begin{array}{l}\text { Analysis } \\
\text { requirement of "Mirunda" } \\
\text { poles }\end{array}$ \\
\cline { 3 - 5 } & & No. & $\begin{array}{l}\text { \% of the } \\
\text { optimal to the } \\
\text { actual }\end{array}$ \\
\hline \multirow{2}{*}{1} & Beams & 128 & & 31 \\
\cline { 2 - 5 } & Slabs & 272 & 40 & 34 \\
\cline { 2 - 5 } & Canopies & 91 & 92 & 31 \\
\hline 2 & Beams & 142 & 28 & 33 \\
\cline { 2 - 5 } & Slabs & 318 & 37 & 34 \\
\cline { 2 - 5 } & Canopies & 96 & 106 & 33 \\
\hline \multirow{2}{*}{3} & Beams & 169 & 41 & 24 \\
\cline { 2 - 5 } & Slabs & 416 & 149 & 35 \\
\cline { 2 - 5 } & Canopies & 102 & 29 & 28 \\
\hline
\end{tabular}

\section{RECOMMENDATIONS}

The investigation results above indicate that the required quantity of "Mirunda" poles as formwork to support freshly casted reinforced concrete slabs, beams and canopies amounts on the average to $31 \%$ of what is currently being applied. This calls for a major recommendation to undertake the analysis in order to establish the exact requirement or to reduce the timber quantity accordingly. In the latter case the recommended average diameter of the poles should range between $63 \mathrm{~mm}-70 \mathrm{~mm}$, whereas the spacing of the poles should not exceed $1000 \mathrm{~mm}$.

\section{LIMITATIONS OF THE STUDY}

The author recognizes the existing site conditions with regard to the two variables affecting the uniformity of the timber poles, namely;

Some timber poles on site are not properly seasoned Some "Mirunda" poles have unwanted inclinations of various divergences.

The two named variables, also verified by Findlay (1974) as the normal timber properties, have adverse effects on the load bearing capacity of the timber poles as formwork structures. To this effect the following measures have been put in place, which include for scenario (i) to establish the moisture content of the "Mirunda"s, and this largely is dependent on the storage system. "Mirunda"s should be obtained at covered storage yards where the moisture content has been demonstrated to fall generally below $30 \%$. For the scenario (ii) the visual selection of straight "Mirunda"s has demonstrated to limit the existence of inclinations to maximal $2 \mathrm{~cm}$.
In this regard a safety factor for the inclination has been considered as in-built in the analysis.

\section{CONCLUSIONS}

For building and construction the use of "Mirunda" poles as structural formworks has gained common practice not only in Tanzania as reflected by Campbel and Malde (1971) but also in the Eastern Africa Region for two main reasons:

1) "Mirunda" trees are very common and favourable to re-forestation campaign because of climatic compatibility to most parts of the region.

2) The price of a "Mirunda" poles is comparatively affordable amongst the rural community (approximately 0.5 US $\$$ per pole).

The problem that "Mirunda" poles have been used massively has been addressed by this initial investigation, the results of which will serve as a guidance on the material requirement on site.

From the investigations and subsequent analysis, the "Mirunda" formwork poles as currently used can be rationally reduced up to $31 \%$ to support freshly casted reinforced concrete slabs. The investigation was based on laboratory tests for randomly selected timber poles samples from street vendors.

There is a demand for further investigations with regard to the quality control of the material, which largely depend on the storage conditions by vendors as well as classification of the poles in accordance to 
the size. Lastly a close follow-up on the performance and utilization of this structural guidance must be undertaken.

\section{REFERENCES}

BS 6399: Part 1, (984)

Loading for Buildings

Part 1: Code of Practice for dead and Imposed Loads
Campbell, P.A., and Malde, K., (1971)

Timber for Building in Tanzania

Ministry of Natural Resources and Tourism

Findlay, W.P.K., (1974)

Timber: Properties and Uses

William Clowes \& Sons Ltd. London

Harold Ernest Desch, (1981)

Timber; its structure, properties and utilization

The Mac Millan Press Ltd. London. Sixth Edition 